\title{
Differential Susceptibility of Diverse Salix spp. to Melampsora americana and Melampsora paradoxa
}

\author{
Chase R. Crowell, ${ }^{1}$ Mariami M. Bekauri, ${ }^{1}$ Ali R. Cala, ${ }^{1}$ Patrick McMullen,,${ }^{1,2}$ Lawrence B. Smart, ${ }^{3}$ and Christine D. Smart ${ }^{1, \dagger}$ \\ ${ }^{1}$ Plant Pathology and Plant-Microbe Biology Section, School of Integrative Plant Science, Cornell University, Cornell AgriTech, \\ Geneva, NY 14456 \\ ${ }^{2}$ Department of Biology, Lebanon Valley College, Annville, PA 17003 \\ ${ }^{3}$ Horticulture Section, School of Integrative Plant Science, Cornell University, Cornell AgriTech, Geneva, NY 14456
}

\begin{abstract}
Melampsora spp. willow rust is the most serious disease of shrub willow bioenergy production in the northeastern United States. Recent phylogenetic studies have identified several Melampsora spp. present on willow in the Northeast; however, in-depth understanding of Melampsora spp. host susceptibility remain unresolved. In this study, a panel of 82 rust isolates collected from the northeastern United States were genotyped via

there is potential for rust resistance breeding using the Salix spp. taxa assayed. Additionally, leaf morphology traits of these Salix spp. hosts were quantified for correlation analysis, revealing that trichome density and stomata density are possible contributors to resistance. This work provides foundational rust pathology information, which is crucial for $M$. americana resistance breeding.
\end{abstract} ribosomal DNA sequencing and a subset of these isolates were assayed for host susceptibility. This work revealed that Melampsora americana is the most prevalent species in the sampled geographic region and that
Keywords: bioenergy, Melampsora willow rust, pathogen diversity, rust resistance breeding, shrub willow
Short-rotation coppice (SRC) bioenergy crops in the family Salicaceae produce ligno-cellulosic energy feedstocks that provide alternatives to fossil fuel-based energy sources targeted for the reduction of greenhouse emissions contributing to climate change. Of these, shrub willow (Salix spp., subgenus Vetrix) is of particular interest as an SRC feedstock in the northeastern United States due to its ability to grow optimally on marginal lands, high yields (Fabio et al. 2016; Serapiglia et al. 2013; Stoof et al. 2015), ability to reduce nutrient run-off (Adegbidi et al. 2001), and favorable carbon emission ratios (Djomo et al. 2011). Salix is a highly heterozygous, dioecious genus with ample opportunities for genetic improvement through traditional breeding and hybridization (Fabio et al. 2016; Karp et al. 2011; Serapiglia et al. 2013). Additionally, Salix is a highly diverse genus with hundreds of species on six continents (Dickmann and Kuzovkina 2014; Kuzovkina et al. 2008). Various Salix spp. from around the world grow well in the northeastern United States, and primarily originate from the northern latitudes of Europe and Asia. Of these, Salix purpurea, a European shrub of particular interest for breeding purposes, was introduced and naturalized in New York State in the 1840s (Brown 1921). Breeding efforts are ongoing to maximize yield in regions across the North America while simultaneously identifying genetic resistance to pests and pathogens (Cameron et al. 2008; Serapiglia et al. 2013), the most threatening of which is willow rust caused by fungal pathogens in the genus $\mathrm{Mel}$ ampsora (McCracken and Dawson 1997; Pei and McCracken 2005).

${ }^{\dagger}$ Corresponding author: C. D. Smart; cds14@ cornell.edu

Funding: This work was funded by United States Department of Agriculture (USDA) National Institute of Food and Agriculture (NIFA) grants (201567009-23957 and 2019-67011-29698).

*The $\boldsymbol{e}$-Xtra logo stands for "electronic extra" and indicates there are supplementary materials published online.

The author(s) declare no conflict of interest.

Accepted for publication 4 May 2020.

(C) 2020 The American Phytopathological Society
Willow rust is the most devastating pathogen of shrub willow bioenergy feedstock, leading to complete defoliation and reduction of yield up to $50 \%$ in extreme cases (Verwijst 1990). Melampsora spp. rusts on shrub willow are macrocyclic and heteroecious, with rapid secondary spread via asexual uredospores (Pei and McCracken 2005). Control of this pathogen is limited to resistance breeding and polyculture, because application of fungicides is not cost effective (McCracken and Dawson 1997, 2003; Pei et al. 1996; Smart and Cameron 2008). Species within the genus Melampsora alternate on a wide range of hosts from trees such as Abies, Larix, Ribes, and Saxifraga spp. to Rosids, including Viola and Euonymus spp. (Pei and McCracken 2005). With ample availability of these alternate hosts in the northeastern United States, there is opportunity for various rust species to occupy similar geographic regions and possibly infect the same Salix hosts. Melampsora spp. taxonomy appears overlapping and ambiguous in many cases, leading to the use of large species complexes containing forma specialis to resolve groups by host specificity (Kenaley et al. 2014; Pei et al. 1996). The Melampsora epitea complex, historically comprising all North American Melampsora rust isolates, has recently been shown inadequate to describe the complexity in rust populations in the United States and Canada (Bennett et al. 2011; Kenaley et al. 2014; Zhao et al. 2017). In the northeastern United States, Kenaley et al. (2014) resolved this large species complex using internal transcribed spacer (ITS) sequencing and phylogenetic reconstruction into three distinct taxa: M. americana alternating on Abies balsamea, M. paradoxa alternating on Larix spp., and a third loosely defined taxa alternating on Ribes spp. However, the host range of these newly defined species and relative impact of each rust species in the northeastern United States is still unknown, unlike other members of the $M$. epitea complex in other regions of the world (McCracken and Dawson 2003; Pei et al. 1996, 2004; Zhao et al. 2017). This necessitates further investigation into these specific species and their potential for disease in the northeastern United States.

Little is known about the resistance and susceptibility of Salix spp. taxa to North American populations of Melampsora rust. The vast majority of work in shrub willow resistance has focused on S. viminalis and $S$. schwerinii susceptibility to European rust populations (Martin et al. 2016; McCracken and Dawson 1997; Pei et al. 1996); however, these Salix spp. are not deployed in North America due to susceptibility to potato leaf hopper. Instead, inferences on 
Table 1. Melampsora spp. isolate collection

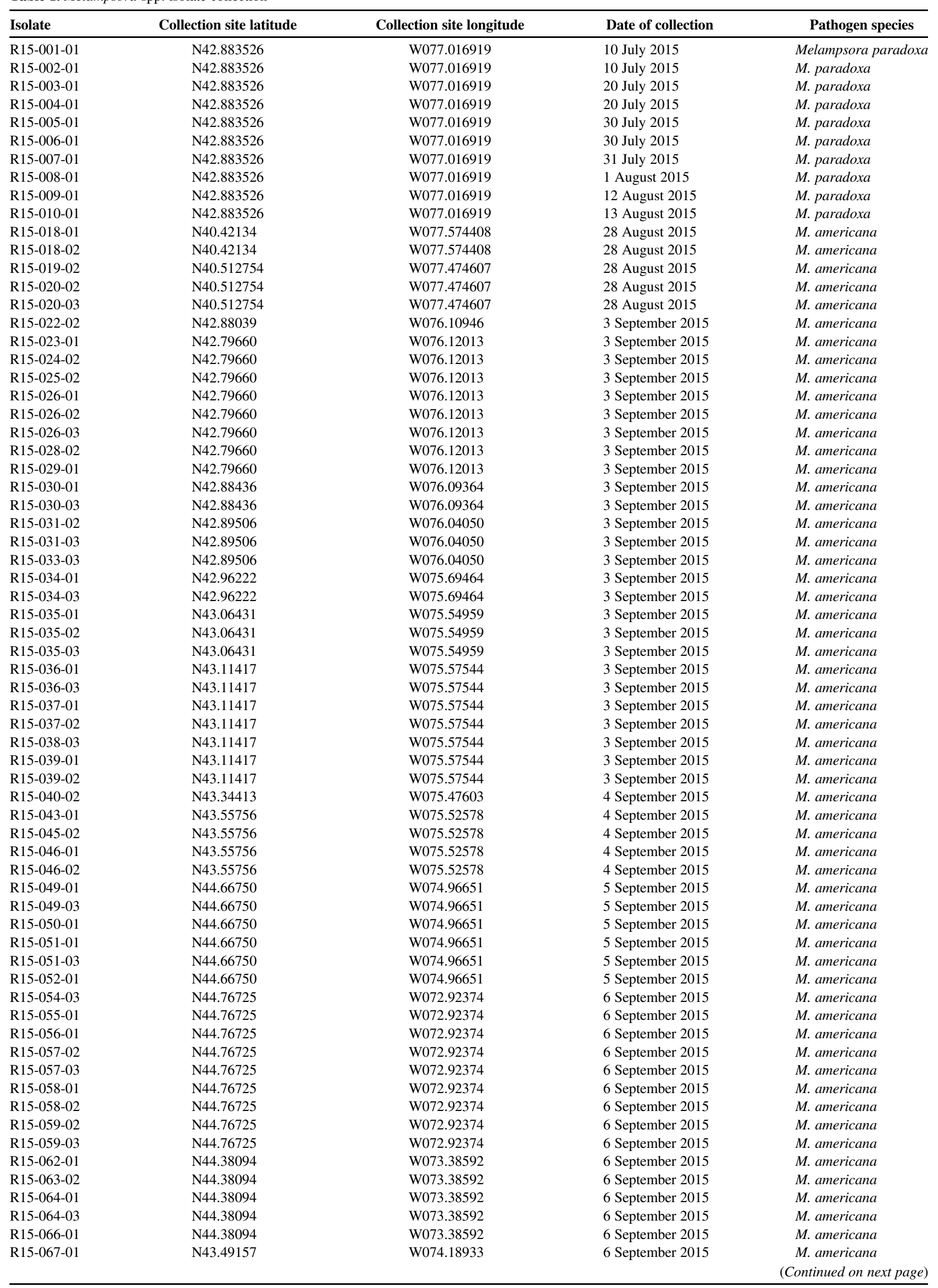


mechanisms of rust resistance can be made in shrub willow by studying the closely related hybrid poplar, for which there is a greater wealth of information available. The major qualitative and quantitative resistance genes, $R_{I}$ and $R_{u s}$, respectively (Dowkiw and Bastien 2004; Pichot and Teissier du Cros 1993), have been identified and fine-mapped to a region of chromosome 19 , where they were discovered to be nucleotide-binding site leucine-rich repeat resistance genes (Bresson et al. 2011). Since these identifications, large mapping studies have been completed to identify further rust resistance candidates (Chen et al. 2019; Mantia et al. 2013), and techniques such as RNA sequencing and metabolomics have been used to further investigate poplar candidates involved in defense and susceptibility to rust (Chen et al. 2016; Li et al. 2016; Petre et al. 2012; Ullah et al. 2019). Due to relatedness between host species, we hypothesize that major quantitative and qualitative resistances exist in Salix spp. to northeastern United States populations of Melampsora rust, and that the initial discovery of these resistances will bear future investigations into specific mechanisms of resistance. In the absence of chemical control, the detection and deployment of rust resistance to regional populations of Melampsora leaf rust in various shrub willow species is of vital importance for large-scale shrub willow cultivation.

The objectives of this study were to (i) determine the most prevalent species of Melampsora rust on S. purpurea in the northeastern United States, (ii) determine the relative levels of resistance of Salix spp. to select Melampsora spp. isolates, (iii) observe segregation of resistance in mapping $F_{1}$ hybrid Salix populations, and (iv) investigate host morphological characteristics potentially affecting rust infection.

\section{Materials and Methods}

Melampsora isolates used in this study. Eighty-six Melampsora isolates were collected from wild and cultivated $S$. purpurea throughout the northeast United States in summer 2015 (Table 1). Uredospores from naturally infected leaves were paintbrush inoculated on the abaxial surface of detached uninfected leaves collected from S. purpurea 'Fish Creek' plants that were grown in a greenhouse with cycles of $14 \mathrm{~h}$ of light and $10 \mathrm{~h}$ of darkness. Each of the 82 isolates went through three successive rounds of single-pustule inoculations to ensure that they were not mixed cultures. Each unique isolate was propagated on detached leaves in an individual water agar Petri dish to prevent isolate cross-contamination and provide $100 \%$ humidity for successful infection. These inoculated detached leaves in Petri dishes were incubated in MLR-352H-PA growth chambers (Panasonic Corporation, Newark, NJ, U.S.A.) at $16^{\circ} \mathrm{C}$ and $80 \mu \mathrm{E} \mathrm{m}^{-2} \mathrm{~s}^{-1}$ for cycles of $16 \mathrm{~h}$ of light and $8 \mathrm{~h}$ of darkness (Pei et al. 2002). Pure culture uredospores of each isolate were collected using a cyclone spore collector (Geoff Harms, Physics Laboratory, University of Minnesota, St. Paul, MN, U.S.A.) attached to a WP6111560 electric vacuum pump (MilliporeSigma, Burlington, MA, U.S.A.). The cyclone spore collector was thoroughly cleaned and sterilized with $70 \%$ ethanol before each isolate uredospore collection.
DNA extraction and internal transcribed spacer sequencing. Uredospores ( $5 \mathrm{mg}$ per $0.5-\mathrm{ml}$ microcentrifuge tube) were dried for at least $4 \mathrm{~h}$ in a desiccator. DNA was extracted using the method of Duplessis et al. (2011). Briefly, uredospores were transferred to a 2-ml microcentrifuge tube containing approximately 20-by-0.2$\mathrm{mm}$ silica beads and approximately 3-by-0.3-mm silica beads, disrupted using a Retsch upright TissueLyser (Retsch Inc., Newton, PA, U.S.A.) and cetyltrimethylammonium bromide (CTAB) lysis buffer $(500 \mu \mathrm{l}$ of $0.1 \mathrm{M}$ Tris [pH 9], $1.43 \mathrm{M} \mathrm{NaCl}, 0.02 \mathrm{M}$ EDTA [pH 8], and $2 \%$ [wt/vol] CTAB) was added to the mixture and incubated in a water bath for $30 \mathrm{~min}$ at $65^{\circ} \mathrm{C}$. Samples were extracted with 50:50 (vol/vol) phenol/chloroform/isoamyl alcohol (25:24:1), followed by 50:50 (vol/vol) chloroform/isoamyl alcohol (24:1). Samples were treated with RNAse I (Thermo Fisher, Waltham, MA, U.S.A.) and DNA was precipitated with isopropanol. Resulting DNA was PCR amplified using primers ITS4br (Vialle et al. 2009) and Fun18f (Pitkäranta et al. 2008) following parameters described in Kenaley et al. (2014). Resulting PCR amplicons were purified using the DNA Clean \& Concentrator (Zymo Research, Irvine, CA, U.S.A.) PCR cleanup kit and sequenced using Sanger Sequencing at the Cornell University Institute of Biotechnology. Consensus sequences for each isolate were aligned using Geneious 10.2.2 MUSCLE alignment software (https://www.geneious.com) with a maximum of eight iterations. A neighbor-joining tree was generated using Tamuri-Nei genetic distance model with 999 bootstraps and a support threshold of $50 \%$.

Resistance assay. A subset of Salix genotypes described by Carlson et al. (2019) representing a wide range of species-S. purpurea (Europe), S. koriyanagi (Asia), S. udensis (Asia), S. suchowensis (Asia), S. integra (Asia), and S. viminalis (Europe)—was selected for resistance assays (Table 2). Plants of each host were grown in a greenhouse as described above and five mature leaves were collected from each host genotype for each rust isolate tested. Four rust isolates (R15-006, R15-033-03, R15-043-01, and R15-085-03) were selected

Table 2. Salix spp. taxa information

\begin{tabular}{llllc}
\hline Parent number & \multicolumn{1}{c}{ Parent ID } & \multicolumn{1}{c}{ Species } & \multicolumn{1}{c}{ Sex } & Ploidy \\
\hline 1 & 94001 & Salix purpurea & Male & $2 \mathrm{n}$ \\
2 & $07-\mathrm{MBG}$-5027 & S. viminalis & Female & $2 \mathrm{n}$ \\
3 & P294 & S. alberti & Female & $2 \mathrm{n}$ \\
4 & Jorr & S. viminalis & Male & $2 \mathrm{n}$ \\
5 & P336 & S. integra & Female & $2 \mathrm{n}$ \\
6 & Sekka & S. udensis & Male & $2 \mathrm{n}$ \\
7 & 94006 & S. purpurea & Female & $2 \mathrm{n}$ \\
8 & $04-\mathrm{FF}-016$ & S. koriyanagi & Male & $2 \mathrm{n}$ \\
9 & P295 & S. suchowensis & Female & $2 \mathrm{n}$ \\
10 & P63 & S. suchowensis & Male & $2 \mathrm{n}$ \\
11 & Fish Creek & S. purpurea & Male & $2 \mathrm{n}$ \\
12 & SH3 & S. koriyanagi & Female & $2 \mathrm{n}$ \\
\hline
\end{tabular}

Table 1. (Continued from previous page)

\begin{tabular}{|c|c|c|c|c|}
\hline Isolate & Collection site latitude & Collection site longitude & Date of collection & Pathogen species \\
\hline R15-067-02 & N43.49157 & W074.18933 & 6 September 2015 & M. americana \\
\hline R15-069-03 & N43.37970 & W074.65100 & 6 September 2015 & M. americana \\
\hline R15-085-03 & N45.46455 & W087.12750 & 29 September 2015 & M. americana \\
\hline R15-091-01 & $\mathrm{N} 42.22261$ & W079.29156 & 2 October 2015 & M. americana \\
\hline R15-091-02 & $\mathrm{N} 42.22261$ & W079.29156 & 2 October 2015 & M. americana \\
\hline R15-091-03 & $\mathrm{N} 42.22261$ & W079.29156 & 2 October 2015 & M. americana \\
\hline R15-092-01 & $\mathrm{N} 42.22261$ & W079.29156 & 2 October 2015 & M. americana \\
\hline R15-094-01 & N42.22261 & W079.29156 & 2 October 2015 & M. americana \\
\hline R15-094-02 & N42.22261 & W079.29156 & 2 October 2015 & M. americana \\
\hline R15-095-01 & $\mathrm{N} 42.22261$ & W079.29156 & 2 October 2015 & M. americana \\
\hline R15-097-02 & N42.22261 & W079.29156 & 2 October 2015 & M. americana \\
\hline R15-099-01 & N42.22261 & W079.29156 & 2 October 2015 & M. americana \\
\hline R15-099-02 & N42.22261 & W079.29156 & 2 October 2015 & M. americana \\
\hline R15-100-01 & $\mathrm{N} 42.22261$ & W079.29156 & 2 October 2015 & M. americana \\
\hline
\end{tabular}


for this experiment based on geographic origin and species identification was determined by ITS sequencing. Uredospores of each of the four isolates were increased on Fish Creek and spores were collected using the cyclone spore collector as described above. Five leaves of each genotype were inoculated with collected spores (1 mg per leaf) in a single water agar Petri dish and uredospore coverage was approximated visually and recorded daily across each set of inoculated host leaves. Detached-leaf assays, as opposed to whole-plant assays, were previously shown to yield similar resistance results (Pei et al. 2004). These ratings were used to calculate area under the disease progress curve (AUDPC) for each replicate (Madden et al. 2007). This experiment was performed three times for each host and rust isolate combination and an average AUDPC was calculated. A generalized linear model was generated using the glm function in R 3.6.1, with AUDPC as a response variable and rep as a random variable ( $\mathrm{R}$ Core Team 2013). Tukey's honest significant difference (HSD) tests $(P<$ $0.05)$ were performed using HSD.test function in R package "Agricolae" (Mendiburu 2015).

Six Salix $\mathrm{F}_{1}$ hybrid mapping populations, as described by Fabio et al. (2019), were surveyed to observe segregation of resistance to M. americana (Table 3). One rust isolate, R15-033-03, was chosen for further investigation due to its homogeneity of virulence patterns among the $M$. americana species isolates. Ten progeny were selected at random from each of the six $F_{1}$ hybrid populations and were grown from cutting in the greenhouse as described above, with the exception of family $13 X-426$ and family $11 X-407$, in which nine progeny were surveyed in virulence assays as described above, except only two leaves of each genotype were inoculated. Two leaves from each genotype were collected and inoculated with $1 \mathrm{mg}$ of spore per leaf within a single water agar Petri dish using methods described above. Uredospore coverage was approximated visually and recorded daily across tree replicates in each of the sets of inoculated host leaves. These ratings were used to calculate AUDPC for each replicate. The experiment was completed three times for each host genotype and averaged to calculate average AUDPC. Statistical calculations were performed as described above.

Stomatal and trichome density observations. Stomatal and trichome densities quantified for each of 12 Salix genotypes (Table 2) used in the virulence experiments described above were also assayed for. Stomatal counts were determined by microscopy on an Olympus CX31 Upright Microscope affixed with an Olympus DP20 Digital Camera (Olympus, Tokyo, Japan) and the online stomata quantification program "StomataCounter" (Fetter et al. 2019). For each host genotype, two leaves were collected and nail polish peels were generated for both abaxial and adaxial surfaces of each leaf. Ten micrographs were taken at $\times 40$ for each leaf peel, resulting in 20 micrographs per host genotype for both abaxial and adaxial surfaces. Trichome density was determined visually at $\times 40$ using a scale to estimate trichome density ( $0=0$ trichomes/field, $1=1$ to 25 trichomes/field, and $2=>25$ trichomes/field).

\section{Results}

Isolate collection and identification. In total, 82 rust isolates from New York, Pennsylvania, Michigan, and Vermont were successfully cultured using single pustule isolations and maintained on detached leaves of Fish Creek. High-quality DNA was extracted, the ITS region was PCR amplified, and those sequenced amplicons were species resolved via neighbor-joining tree phylogenetic reconstruction, including ITS sequences of known Melampsora rust species M. americana (GenBank: KF170128.1), M. paradoxa (GenBank: KF170078.1), M. ribisii-purpurea (GenBank: AY444770.2), M. medusae (GenBank: AF087711), and M. occidentalis (GenBank: AF087710.1) (Supplementary Fig. S1). In all, 10 isolates clustered with the known $M$. paradoxa ITS sequence ( $99.8 \%$ bootstrap support), while all 72 other isolates clustered with the $M$. americana ITS sequence (Table 1). Variation between the isolates clustering with the $M$. americana reference sequence correlated with regions of sequence ambiguity within the Sanger sequencing data. All isolates clustering with $M$. paradoxa were the first isolates collected in summer 2015 from a single location with identical sequences, and the isolates clustering with $M$. americana were collected from all locations throughout summer 2015 (Table 1). Sequences showed extremely little diversity within the two clades across these amplified products, with a clear delineation between the M. americana and $M$. paradoxa isolates. None of the isolates clustered with the $\mathrm{Eu}-$ ropean Melampsora sp. M. ribisii-purpurea, nor did they cluster with the distantly related poplar rust species $M$. medusae or $M$. occidentalis.

Virulence assay. Mean AUDPC across a panel of 12 diverse willow taxa (Table 2) was calculated for M. americana isolates R15033-03, R15-043-01, and R15-085-03 and M. paradoxa isolate R15-006 (Fig. 1). Across the genotypes challenged with M. americana isolates, both S. viminalis 07-MBG-0527 and 'Jorr', S. udensis 'Sekka', and S. suchowensis P63 showed significantly low levels of rust infection. S. suchowensis P295 was the only genotype that was significantly susceptible to all three $M$. americana isolates. All resistance profiles across genotypes inoculated with $M$. americana rust isolates showed similar patterns; however, genotypes 94001, 04FF-018, and Fish Creek showed some statistical differences depending on which $M$. americana rust isolate was used for inoculation (Fig. 2). Nearly all genotypes started showing symptoms of rust infection at 8 days postinoculation (dpi), with the exception of genotype P336, which showed delayed symptom development until $10 \mathrm{dpi}$. The resistance profiles of genotypes inoculated with $M$. americana isolates dramatically contrasts with the $M$. paradoxa results, in which all genotypes showed low susceptibility, with the exception of Fish Creek, which was extremely susceptible to R15006-01 (Fig. 2).

Segregation of resistance assay. The diverse Salix genotypes were crossed with $S$. purpurea to generate $\mathrm{F}_{1}$ hybrid mapping populations (Table 3) (Fabio et al. 2019). In family 13X-358, individuals 5 and 7 were nearly completely resistant and individuals 4,9 , and 10 were highly susceptible, with mean AUDPC significantly greater than the mean of the most susceptible parent. Family $13 X-426$ had an overall lower level of susceptibility, where individuals 3, 7, and 8 separated in the low susceptibility category, and all progeny of this family showed a phenotype equal to or between the values of the parents. In contrast, individuals 3,4 , and 5 of family $13 \mathrm{X}-440$ were highly resistant and the mean of all 10 individuals was lower than either parent. Individuals 3 and 6 of family 13X-438 and individuals 8 and 10 of $13 \mathrm{X}-443$ showed similarly strong resistance, while individuals 2 and 1, respectively, showed low resistance. Both of these families showed heterosis compared with the respective parental phenotypes. Finally, family $11 \mathrm{X}-407$ had four individuals with strong resistance, including individuals $2,3,4$, and 9; individual 7 was intermediate and individual 6 had low resistance. Variation among progeny in all families suggested segregation of resistance,

Table 3. $F_{1}$ hybrid mapping population information

\begin{tabular}{lcclll}
\hline Family & Number of individuals & Female cross & Female species & Male cross & Male species \\
\hline $13 x-358$ & 10 & 94006 & Salix purpurea & 04-BN-051 & S. udensis \\
$13 \mathrm{x}-426$ & 10 & $\mathrm{P} 336$ & S. integra & 94001 & S. purpurea \\
$13 \mathrm{x}-438$ & 10 & 94006 & S. purpurea & 04-FF-016 & S. purpuranai \\
$13 \mathrm{x}-440$ & 10 & $\mathrm{P} 295$ & S. suchowensis & 94001 & S. purpurea \\
$13 \mathrm{x}-443$ & 10 & $\mathrm{P} 294$ & S. alberti & 94001 & Sorr \\
$11 \mathrm{x}-407$ & 94006 & S. purpurea & viminalis \\
\hline
\end{tabular}


with family $13 \mathrm{X}-440$ having the lowest and family $13 \mathrm{X}-358$ the greatest mean AUDPC among all families (Fig. 2). Symptom development was consistent across all families and did not appear until 8 dpi for all individuals.

Stomata and trichome surveys. Adaxial and abaxial mean stomatal densities, as well as trichome density, were calculated for the 12 Salix spp. genotypes used in resistance assays (Table 2), with the exception of Jorr, which produced copious trichomes that interfered with stomata quantification (Fig. 3). The greatest number of adaxial stomata was found on genotype P295, with an average of 33 stomata per microscope field. Either 0 or 1 stomata, in total, was observed in all microscope fields of genotypes SH3, P336, Sekka, and 04-FF-016. Abaxial stomata densities did not correlate with adaxial densities, because taxa P294 had the highest abaxial average stomata count with 97 per microscope field. The lowest average abaxial counts were shared by Sekka and 04-FF-016, with 14 and 23 stomates per microscope field, respectively. Taxa 94001, 07-MBG5027, P336, 94006, P295, P63, Fish Creek, and SH3 showed intermediate average abaxial stomata counts ranging from 30 to 58 . AUDPC values for all three $M$. americana isolates were independently correlated, as well as combined and correlated, with stomatal density. None of the correlations of the individual rust isolates between stomatal density (either adaxial or abaxial) and disease susceptibility were significantly correlated using Pearson's correlation. However, when all three isolates were correlated together (Fig. $3 \mathrm{D})$, adaxial stomata density was significantly positively correlated $(R=0.42)$ to disease susceptibility $(P<0.05)$.
Trichome density was calculated on a scale where leaves lacking trichomes were scored 0 , leaves with 1 to 25 trichomes per microscope view were scored 1 , and $>25$ trichomes were scored a 2 . Both 07-MBG-5027 and P63 had the highest score for trichome count; P294, Sekka, and P295 showed an intermediate level of trichomes; and all remaining taxa did not show any trichomes. When trichome density was correlated to disease susceptibility, isolate R15-043-01 and all three isolates together were significantly negatively correlated ( $R=-0.67$ and -0.55 , respectively).

\section{Discussion}

This is the first comprehensive survey of Melampsora spp. diversity on $S$. purpurea, a naturalized species of the northeastern United States. Of the 82 isolates collected, the majority were identified as $M$. americana while a smaller subset was $M$. paradoxa. The $M$. americana isolates were collected across a range of dates from late August until early October 2015 and from multiple locations. In contrast, all $10 \mathrm{M}$. paradoxa isolates were collected from a single location in Geneva, NY in September 2015, much earlier than most of the $M$. americana isolates were collected and when rust severity was low in the fields scouted. This may suggest that there are epidemiological differences between these two rust species, because $M$. paradoxa may release aeciospores to infect its alternative host earlier in the spring than $M$. americana, resulting in earlier disease development. Other cases of species-specific aeciospore release are documented in better studied pathosystems (Berlin et al. 2018; Zhao et al. 2013) and have led to specific control strategies, which
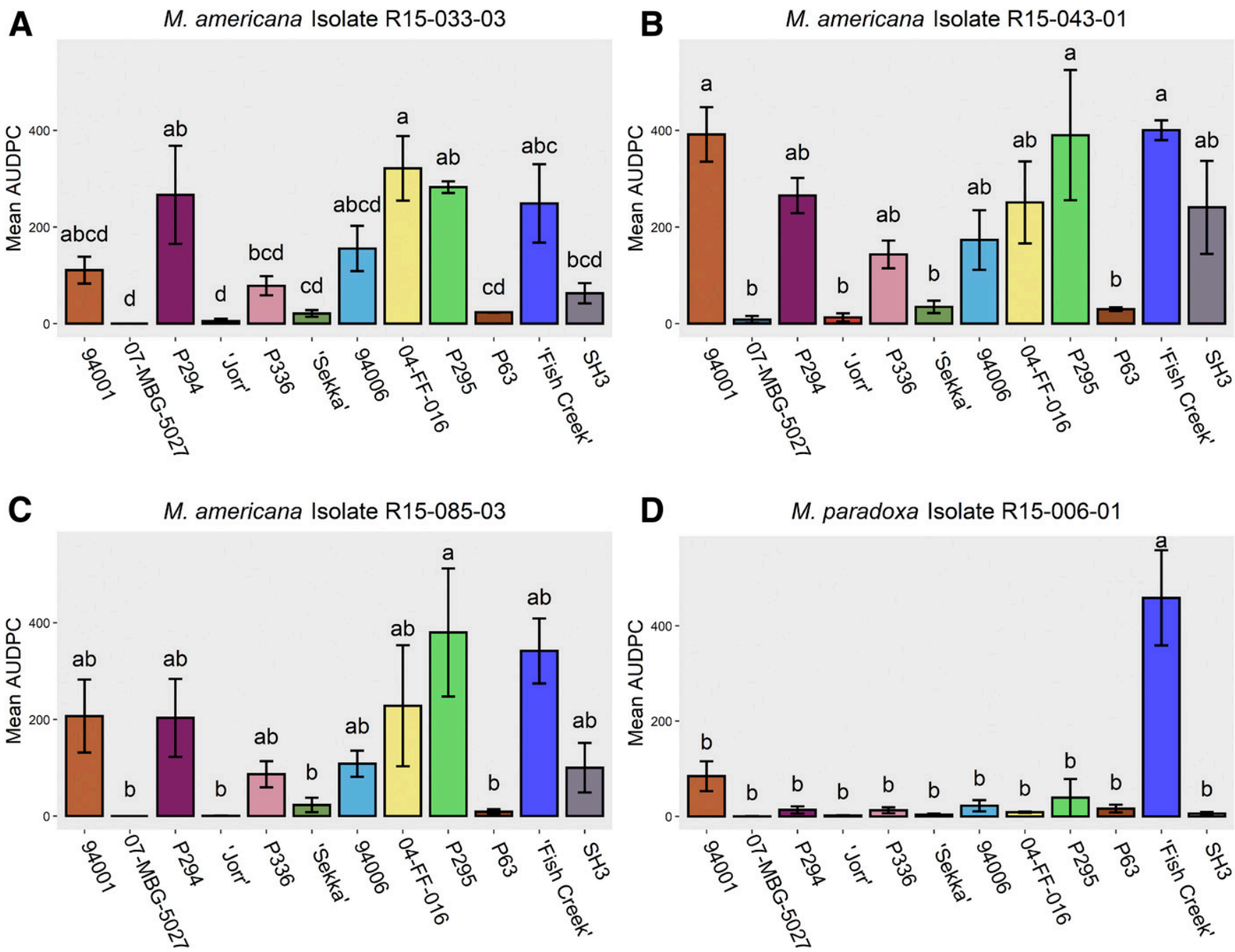

Fig. 1. Mean area under the disease progress curve (AUDPC) of three biological replicates (on 12 diverse Salix spp. taxa) inoculated with Melampsora americana isolates A, R15033-03; B, R15-043-01; and C, R15-085-03 and D, one M. paradoxa isolate, R15-006. Error bars indicate standard error. Significance was determined using Tukey's honestly significant difference, and groupings are assigned by letters designated above error bars. 
mainly consist of the controlled deployment of resistant hosts in annual systems (Kramer et al. 1968; McCallum et al. 2007). Alternatively, some species of rust infecting willow have been known to exhibit stem-infecting variants that forgo overwintering on leaf debris and alternating on a secondary host (Pei et al. 1995). It is possible that $M$. paradoxa rust isolates collected in this study resulted from clonal isolates emerging from stem or bud tissue early in the growing season, before aecial release of $M$. americana. It is curious that we did not identify additional $M$. paradoxa isolates on $S$. purpurea hosts in the same region later in the growing season. One possible explanation is that the $M$. paradoxa isolates were less fit than the $M$. americana isolates and were outcompeted. Based on our resistance assays, it would appear as though the M. americana isolates were able infect a wider range of host genotypes compared

\section{Family $13 X-358$}

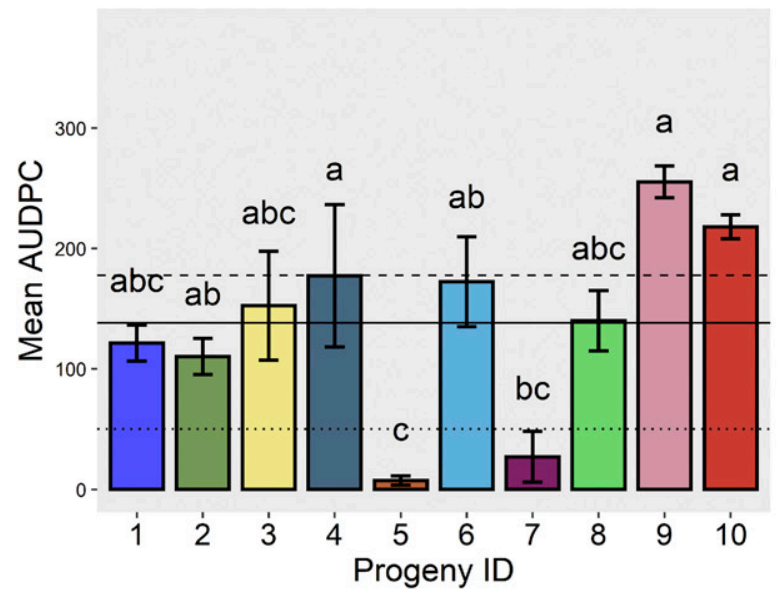

Family $13 \mathrm{X}-438$

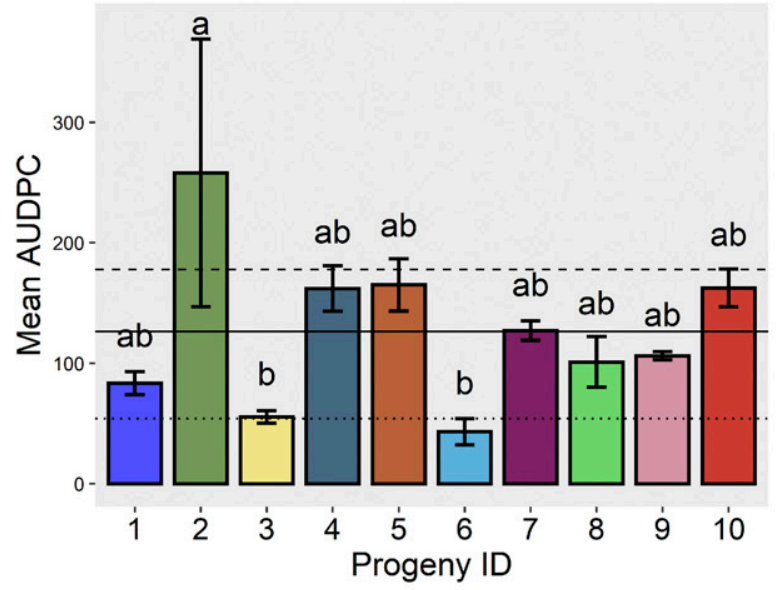

Family 13X-443

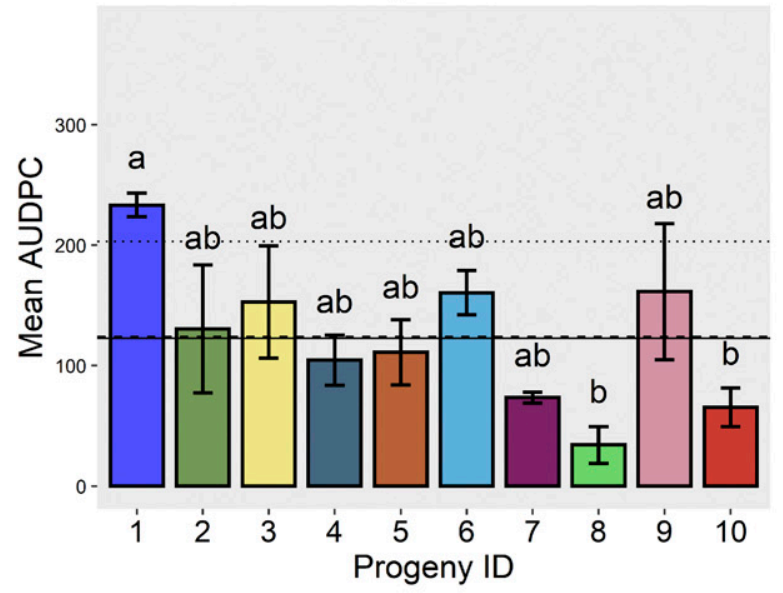

Family 13X-426

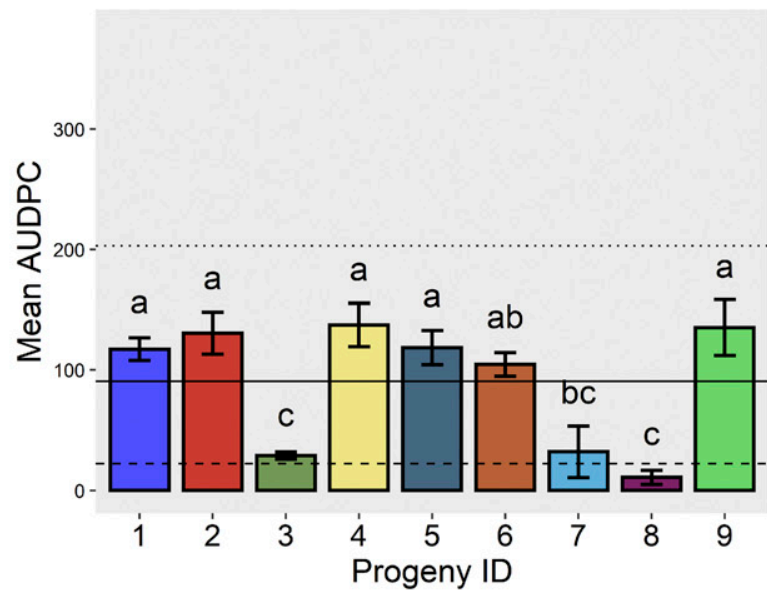

Family $13 \mathrm{X}-440$

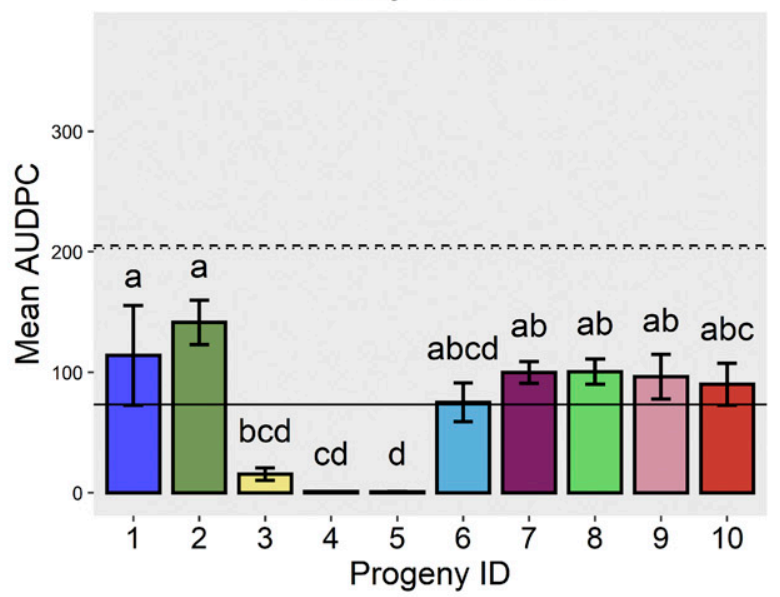

Family 11X-407

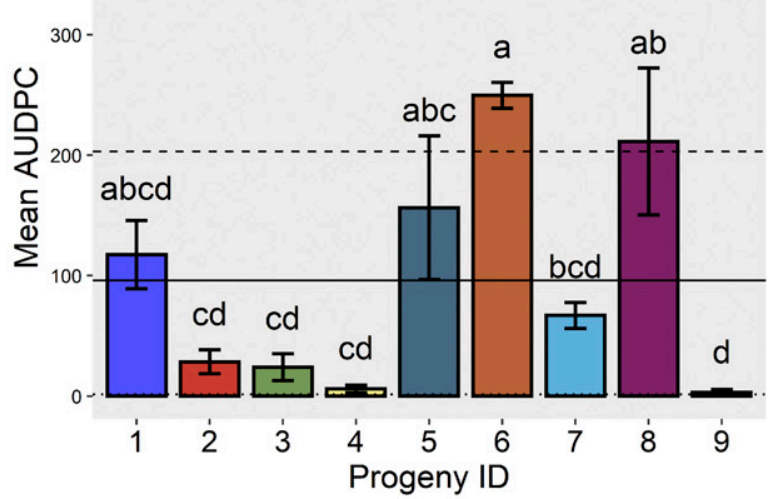

\section{-- Female Parent Mean … Male Parent Mean - Progeny Mean}

Fig. 2. Mean area under the disease progress curve (AUDPC) of three biological replicates on 9 or 10 progeny across six interspecific $F_{1}$ Salix families inoculated with Melampsora americana rust isolate R15-033-03. Error bars indicate standard error. Significance within each family was calculated using Tukey's honestly significant difference and letters above error bars represent statistical groupings. Dotted lines represent the mean disease severity for the male parent, dashed lines represent the mean disease severity for the female parent of each family, and solid lines represent the average disease severity across all progeny of each family. 
with the $M$. paradoxa isolate, possibly providing support to this theory. Yet the identification of these two rust species is relatively recent (Kenaley et al. 2014) and requires further epidemiological studies to understand the differences between these taxa and possible explanations for their geographic and temporal distributions.
On a more fundamental basis, knowledge of the more prevalent species infecting $S$. purpurea is valuable because it provides a framework for population biology investigations for future studies. We know that $M$. americana is macrocyclic and heteroecious alternating on the balsam fir (A. balsamea) (Kenaley et al. 2014), yet we do not know the impact of sexual reproduction and distance of aeciospore
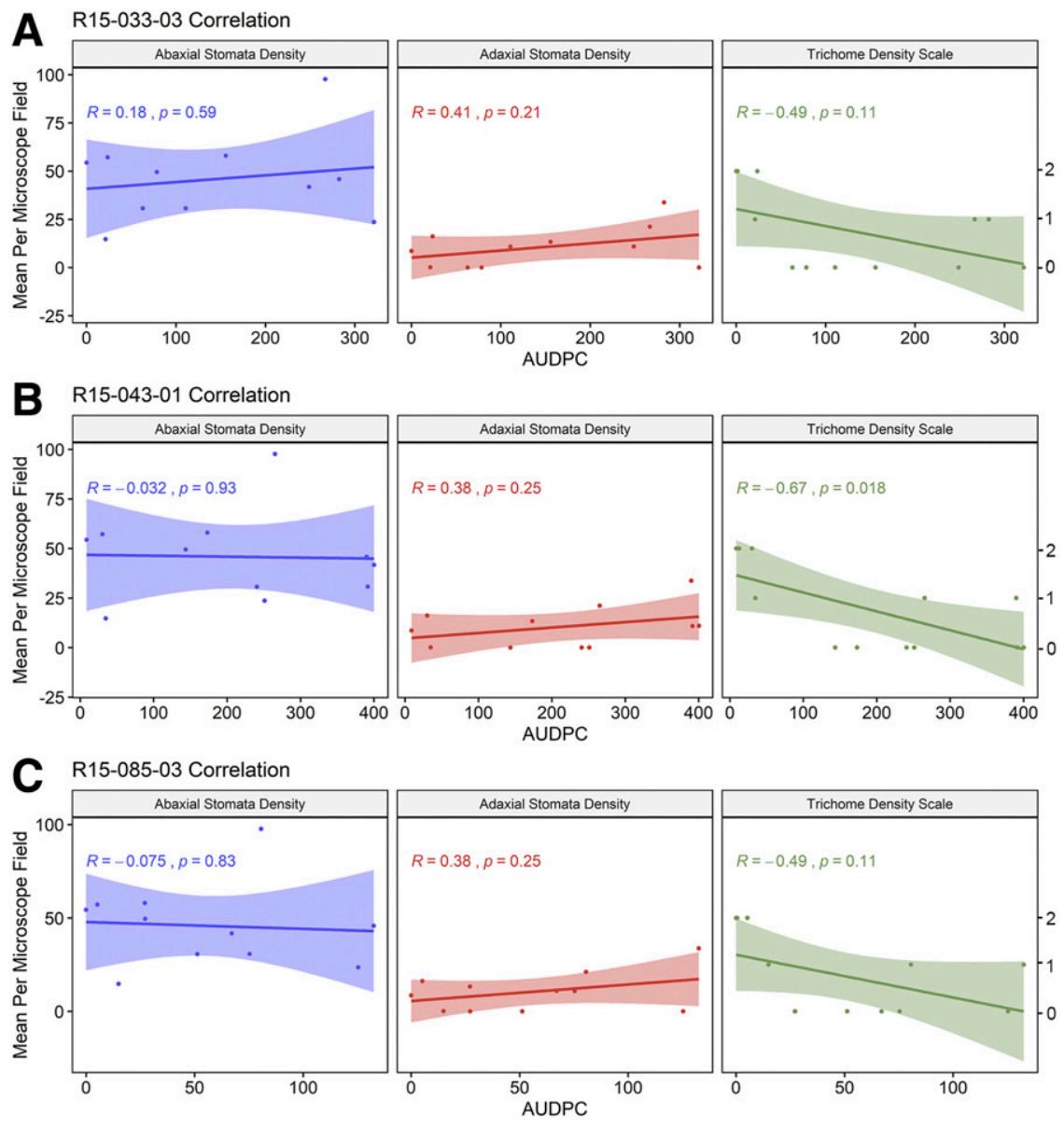

D Three M. americana Together
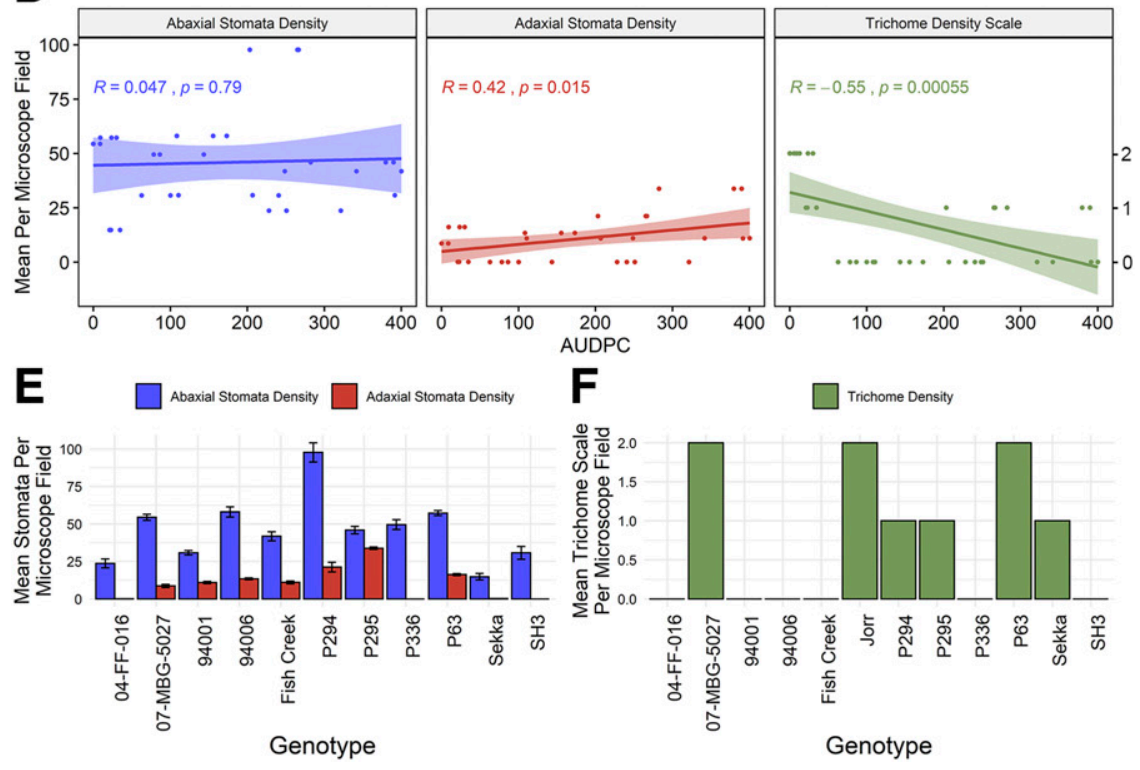

Fig. 3. Linear regression line and 95\% confidence interval of the Pearson's correlation of abaxial and adaxial stomatal density and scaled trichome density per microscope field area under the disease progress curve (AUDPC) for isolates A, R15-033-03; B, R15-043-01; C, R15-085-03; and D, all three Melampsora americana isolates combined. E, Mean abaxial and adaxial stomata density of Salix genotypes assayed with accompanying standard error bars except Jorr. F, Mean scaled trichome density per microscope field for all Salix spp. genotypes used in the resistance assay. 
spread. With this information, it is possible to design experiments that track disease progression and provide preventative practices for shrub willow growers, discouraging the planting of willow stands in close vicinity to balsam fir trees commonly found in Christmas tree plantings. As our understanding of Melampsora rust on Salix spp. willow continues to unfold, we can develop a sense of the epidemiological differences between M. americana and M. paradoxa and use that information to improve rust control for bioenergy production.

Due to our limited observation and collection of M. paradoxa in field isolates from 2015, one representative isolate was chosen for virulence assays. The selected M. americana isolates showed similar virulence patterns across the 12 Salix genotypes surveyed. This might imply that there is limited race specialization within the $M$. americana population and that those isolates express similar effectors or, alternatively, that all isolates surveyed share closely related ancestry despite geographic separation of their collection sites. Additionally, we identified some willow genotypes with a range of resistance phenotypes to these isolates; therefore, it is likely that both vertical and horizontal resistance exist in these genotypes. When the same willow genotypes were inoculated with $M$. paradoxa, nearly all were completely resistant, except Fish Creek, which was susceptible, suggesting vertical resistance. This resistance might provide an explanation for the infrequency of $M$. paradoxa isolates in the field and suggests that $M$. paradoxa plays a minor role in rust epidemics.

Six $F_{1}$ hybrid families were chosen to investigate segregation of the resistance identified in the parents. Most families showed a quantitative pattern of inheritance, with normal distributions centered at the mid-parent mean with a few transgressive sergeants. Of these, families 13X-438 and 11X-407 showed the greatest amount of variation, highlighting them as good candidates for genetic mapping of resistance loci. In contrast, progeny in family $13 \mathrm{X}-440$ exhibited lower disease severity than either parent 94001 or P295. It is possible that this pattern is due to limited sampling of this family but these initial results from randomly selected progeny suggest that there is heterosis for resistance in this family. This warrants further investigation to gain a better understanding of the genetic basis for resistance and the potential for introgression of $M$. americana rust resistance into other pedigrees. Together, these data indicate that rust resistance is widespread across these $\mathrm{F}_{1}$ interspecific hybrid families.

We hypothesized that greater stomatal density would provide more opportunity for pathogen penetration of the leaf tissue, while greater trichome density would impose a physical barrier, inhibiting spore attachment to the leaf surface. These align with previous literature showing that trichome and stomatal density are important morphological factors in rust infections (Shaik 1985; Stenglein et al. 2005; Wynn 1976). Although resistance was identified in the Salix genotypes assayed, the mechanism of the resistance is not yet known. As a result, we chose to investigate variation in those observable morphological phenotypes that might affect the ability of the pathogen to infect. We assayed stomata and trichome densities for the 12 Salix genotypes used in resistance assays and tested the Pearson correlations for these traits. Stomatal density on the adaxial or abaxial leaf surface was not significantly correlated with disease severity for each individual rust isolate; however, the correlation was significant when all isolates were combined. This suggests that there is likely a positive relationship between stomata density and rust susceptibility but greater sampling is required to increase statistical power. There was similar negative correlation between trichome density and rust susceptibility, suggesting that trichomes impose a barrier to infection. However, the association between morphological traits and rust resistance may be more complex than simply stomata and trichome density. For example, Niks and Rubiales (2002) showed that excessive cuticular wax coverage over stomata provided a physical barrier to appressorium penetration in Hordeum chilense. Additionally, trichome shape and function has been known to affect pathogen resistance (Levin 1973; Stenglein et al. 2005). Future investigation should include a larger sampling scheme as well as increased attention to trichome type and cuticular wax to fully investigate the relationship between stomata and trichome densities and rust resistance.
M. americana was the most abundant rust species collected in the northeastern United States on S. purpurea. Salix spp. resistance profiles vary by host genotype and differ dramatically between $M$. americana and M. paradoxa. Resistance in Salix spp. to M. americana isolate R15-033-03 shows quantitative and heterotic patterns of inheritance across the six $\mathrm{F}_{1}$ hybrid mapping populations assayed. Trichome density was significantly correlated and stomata densities were weakly correlated with host resistance to $M$. americana across diverse Salix spp. taxa. This work has laid the groundwork for future Melampsora rust population investigation and resistance breeding in the northeastern United States, with the goal of improved Melampsora rust management through resistant cultivars.

\section{Acknowledgments}

We thank R. Wilk, L. Carlson, D. Fishback, J. Petzoldt, H. Lange, and M. Christiansen for outstanding technical assistance.

\section{Literature Cited}

Adegbidi, H. G., Volk, T. A., White, E. H., Abrahamson, L. P., Briggs, R. D., and Bickelhaupt, D. H. 2001. Biomass and nutrient removal by willow clones in experimental bioenergy plantations in New York State. Biomass Bioenergy 20:399-411.

Bennett, C., Aime, M. C., and Newcombe, G. 2011. Molecular and pathogenic variation within Melampsora on Salix in western North America reveals numerous cryptic species. Mycologia 103:1004-1018.

Berlin, A., Wallenhammar, A. C., and Andersson, B. 2018. Population differentiation of Puccinia coronata between hosts-Implications for the epidemiology of oat crown rust. Eur. J. Plant Pathol. 152:901-907.

Bresson, A., Jorge, V., Dowkiw, A., Guerin, V., Bourgait, I., Tuskan, G. A., and Faivre Rampant, P. 2011. Qualitative and quantitative resistances to leaf rust finely mapped within two nucleotide-binding site leucine-rich repeat (NBSLRR)-rich genomic regions of chromosome 19 in poplar. New Phytol. 192 151-163.

Brown, H. P. 1921. Trees of New York, Native and Naturalized. Technical publication (New York State College of Forestry at Syracuse University) no. 15. Syracuse University Press, Syracuse, NY, U.S.A.

Cameron, K. D., Phillips, I. S., Kopp, R. F., Volk, T. A., Maynard, C. A. Abrahamson, L. P., and Smart, L. B. 2008. Quantitative genetics of traits indicative of biomass production and heterosis in 34 full-sib F1 Salix eriocephala families. BioEnergy Res. 1:80-90.

Carlson, C. H., Gouker, F. E., Crowell, C. R., Evans, L., DiFazio, S. P., Smart, C. D., and Smart, L. B. 2019. Joint linkage and association mapping of complex traits in shrub willow (Salix purpurea L.). Ann. Bot. 124:701-715.

Chen, Q., Wang, J., Li, D., Wang, Z., Wang, F., and Zhang, R. 2019. Molecular characterization of the transcription factors in susceptible poplar infected with virulent Melampsora larici-populina. Int. J. Mol. Sci. 20:4806.

Chen, Z. J., Cao, Z. M., Yu, Z. D., and Yu, D. 2016. Cloning and characterization of defense-related genes from Populus szechuanica infected with rust fungus Melampsora larici-populina. Genet. Mol. Res. 15:1-15.

Dickmann, D. I., and Kuzovkina, J. 2014. Poplars and willows of the world with emphasis on silviculture important species. Pages 8-91 in: Poplars and Willow: Trees for Society and the Environment. J. G. Isebrands and J. Richardson, eds. CABI, Boston, MA, U.S.A.

Djomo, S. N., El Kasmioui, O., and Ceulemans, R. 2011. Energy and greenhouse gas balance of bioenergy production from poplar and willow: A review. GCB Bioenergy 3:181-197.

Dowkiw, A., and Bastien, C. 2004. Characterization of two major genetic factors controlling quantitative resistance to Melampsora larici-populina leaf rust in hybrid poplars: Strain specificity, field expression, combined effects, and relationship with a defeated qualitative resistance gene. Phytopathology 94 1358-1367.

Duplessis, S., Cuomo, C. A., Lin, Y. C., Aerts, A., Tisserant, E., Veneault-Fourrey, C., Joly, D. L., Hacquard, S., Amselem, J., Cantarel, B. L., Chiu, R., Coutinho, P. M., Feaue, N., Field, M., Frey, P., Gelhaye, E., Goldberg, J., Grabherr, M. G., Kodira, C. D., and Martin, F. 2011. Obligate biotrophy features unraveled by the genomic analysis of rust fungi. Proc. Natl. Acad. Sci. U.S.A. 108: 9166-9171

Fabio, E. S., Leary, C. J., and Smart, L. B. 2019. Tolerance of novel inter-specific shrub willow hybrids to water stress. Trees (Berl.) 33:1015-1026.

Fabio, E. S., Volk, T. A., Miller, R. O., Serapiglia, M. J., Gauch, H. G., Van Rees, K. C. J., and Smart, L. B. 2016. Genotype $\times$ environment interaction analysis of North American shrub willow yield trials confirms superior performance of triploid hybrids. GCB Bioenergy 9:445-459.

Fetter, K. C., Eberhardt, S., Barclay, R. S., Wing, S., and Keller, S. R. 2019 StomataCounter: A neural network for automatic stomata identification and counting. New Phytol. 223:1671-1681.

Karp, A., Hanley, S. J., Trybush, S. O., Macalpine, W., Pei, M., and Shield, I. 2011 Genetic improvement of willow for bioenergy and biofuels. J. Integr. Plant Biol. 53:151-165. 
Kenaley, S. C., Smart, L. B., and Hudler, G. W. 2014. Genetic evidence for three discrete taxa of Melampsora (Pucciniales) affecting willows (Salix spp.) in New York State. Fungal Biol. 118:704-720.

Kramer, C. L., Pady, S. M., Clary, R., and Haard, R. 1968. Diurnal periodicity in aeciospore release of certain rusts. Trans. Br. Mycol. Soc. 51:679-687, IN6.

Kuzovkina, Y. A., Weih, M., Romero, M. A., Charles, J., Hurst, S., McIvor, I., and Volk, T. A. 2008. Salix: Botany and global horticulture. Hortic. Rev. (Am. Soc. Hortic. Sci.) 34:447-489.

Levin, D. A. 1973. Role of trichomes in plant defense. Q. Rev. Biol. 48:3-15.

Li, D., Wang, F., Wang, C., Zou, L., Wang, Z., Chen, Q., Niu, C., Zhang, R., Ling, Y., and Wang, B. 2016. MicroRNA-mediated susceptible poplar gene expression regulation associated with the infection of virulent Melampsora larici-populina. BMC Genomics 17:59.

Madden, L. V., Hughes, G., and van den Bosch, F. 2007. The Study of Plant Disease Epidemics. American Phytopathological Society, St. Paul, MN.

Mantia, J., Klápště, J., El-Kassaby, Y. A., Azam, S., Guy, R. D., Douglas, C. J., Mansfield, S. D., and Hamelin, R. 2013. Association analysis identifies Melampsora $\times$ columbiana poplar leaf rust resistance SNPs. PLoS ONE 8:e78423.

Martin, T., Rönnberg-Wästljung, A. C., Stenlid, J., and Samils, B. 2016. Identification of a differentially expressed TIR-NBS-LRR gene in a major QTL associated to leaf rust resistance in Salix. PLoS One 11:e0168776.

McCallum, B. D., Fetch, T., and Chong, J. 2007. Cereal rust control in Canada. Aust. J. Agric. Res. 58:639-647.

McCracken, A. R., and Dawson, W. M. 1997. Growing clonal mixtures of willow to reduce effect of Melampsora epitea var. epitea. Eur. J. For. Pathol. 27:319-329.

McCracken, A. R., and Dawson, W. M. 2003. Rust disease (Melampsora epitea) of willow (Salix spp.) grown as short rotation coppice (SRC) in inter- and intraspecies mixtures. Ann. Appl. Biol. 143:381-393.

Mendiburu, F. D. 2015. agricolae: Statistical Procedures for Agricultural Research. R Package Version 1.2-3.

Niks, R. E., and Rubiales, D. 2002. Potentially durable resistance mechanisms in plants to specialised fungal pathogens. Euphytica 124:201-216.

Pei, M. H., and McCracken, A. R. 2005. Rust Diseases on Willow and Poplar. CAB International, Wallingford, U.K.

Pei, M. H., Royle, D. J., and Hunter, T. 1995. A comparative study of stem- and leaf-infecting forms of Melampsora rust on Salix viminalis in the U.K. Mycol. Res. 99:357-363.

Pei, M. H., Royle, D. J., and Hunter, T. 1996. Pathogenic specialization in Melampsora epitea var. epitea on Salix. Plant Pathol. 45:679-690.

Pei, M. H., Ruiz, C., Bayon, C., and Hunter, T. 2004. Rust resistance in Salix to Melampsora larici-epitea. Plant Pathol. 53:770-779.

Pei, M. H., Ruiz, C., Hunter, T., Arnold, G. M., and Bayon, C. 2002. Quantitative relationships between inoculum of Melampsora larici-epitea and corresponding disease on Salix. Plant Pathol. 51:443-453.

Petre, B., Morin, E., Tisserant, E., Hacquard, S., Da Silva, C., Poulain, J., and Duplessis, S. 2012. RNA-Seq of early-infected poplar leaves by the rust pathogen Melampsora larici-populina uncovers PtSultr3;5, a fungal-induced host sulfate transporter. PLoS One 7:e44408.

Pichot, C., and Teissier du Cros E. 1993. Susceptibility of Populus deltoides BARTR to Melampsora larici-populina and M. alii-populina. I. Qualitative analysis of a $6 \times 6$ factorial mating design. Silvae Genet. 42:179-188.

Pitkäranta, M., Meklin, T., Hyvärinen, A., Paulin, L., Auvinen, P., Nevalainen, A., and Rintala, H. 2008. Analysis of fungal flora in indoor dust by ribosomal DNA sequence analysis, quantitative PCR, and culture. Appl. Environ. Microbiol. 74: 233-244.

R Core Team 2013. R: A language and environment for statistical computing. R Foundation for Statistical Computing, Vienna, Austria.

Serapiglia, M. J., Cameron, K. D., Stipanovic, A. J., Abrahamson, L. P., Volk, T. A., and Smart, L. B. 2013. Yield and woody biomass traits of novel shrub willow hybrids at two contrasting sites. BioEnergy Res. 6:533-546.

Shaik, M. 1985. Race-nonspecific resistance in bean cultivars to races of Uromyces appendiculatus var. appendiculatus and its correlation with leaf epidermal characteristics. Phytopathology 75:478-481.

Smart, L. B., and Cameron, K. D. 2008. Genetic improvement of willow (Salix spp.) as a dedicated bioenergy crop. Pages 377-396 in: Genetic Improvement of Bioenergy Crops. W. Vermerris, ed. Springer Science, Berlin.

Stenglein, S. A., Arambarri, A. M., Menendez Sevillano, M. D. C., and Balatti, P. A. 2005. Leaf epidermal characters related with plant's passive resistance to pathogens vary among accessions of wild beans Phaseolus vulgaris var. aborigineus (Leguminosae-Phaseoleae). Flora 200:285-295.

Stoof, C. R., Richards, B. K., Woodbury, P. B., Fabio, E. S., Brumbach, A. R., Cherney, J., and Steenhuis, T. S. 2015. Untapped potential: Opportunities and challenges for sustainable bioenergy production from marginal lands in the northeast USA. BioEnergy Res. 8:482-501.

Ullah, C., Tsai, C. J., Unsicker, S. B., Xue, L., Reichelt, M., Gershenzon, J., and Hammerbacher, A. 2019. Salicylic acid activates poplar defense against the biotrophic rust fungus Melampsora larici-populina via increased biosynthesis of catechin and proanthocyanidins. New Phytol. 221:960-975.

Verwijst, T. 1990. Clonal differences in the structure of a mixed stand Salix viminalis in response to Melampsora and frost. Can. J. For. Res. 20:602-605.

Vialle, A., Feau, N., Allaire, M., Didukh, M., Martin, F., Moncalvo, J. M., and Hamelin, R. C. 2009. Evaluation of mitochondrial genes as DNA barcode for Basidiomycota. Mol. Ecol. Resour. 9:99-113.

Wynn, W. K. 1976. Appressorium formation over stomates by the bean rust fungus: Response to a surface contact stimulus. Phytopathology 66:136-146.

Zhao, J., Wang, L., Wang, Z., Chen, X., Zhang, H., Yao, J., Zhan, G., Chen, W., Huang, L., and Kang, Z. 2013. Identification of eighteen berberis species as alternate hosts of Puccinia striiformis f. sp. tritici and virulence variation in the pathogen isolates from natural infection of barberry plants in China. Phytopathology 103:927-934.

Zhao, P., Kakishima, M., Wang, Q., and Cai, L. 2017. Resolving the Melampsora epitea complex. Mycologia 109:391-407. 